\title{
Una propuesta práctica para entender, valorar y discernir los enfoques de la enseñanza
}

\section{A Practical Proposal for Understanding, Evaluating and Discerning the Approaches to Teaching}

Alicia Ros Garrido | Departament de Didàctica i Organització Escolar. Universitat de València

口

Recepción: 3 de marzo de 2015 | Revisión: 4 febrero de 2015 | Aceptación/Publicación: 5 de febrero de 2015

Revisores: Karen McMullin. Trent University

Marzia Fiorini. Grupo de Investigación: Aprendizaje y Desarrollo en Contextos Educativos. Universidad de Granada

Correspondencia con los autores: Alicia.Ros@uv.es

\section{Resumen}

La finalidad del artículo es proporcionar una propuesta metodológica para facilitar la comprensión, la valoración y poder discernir los enfoques de la enseñanza propuestos por Fenstermacher y Soltis (1998). En primer lugar se hace referencia a diversas maneras de concebir y clasificar las teorías de enseñanza. En segundo lugar se resaltan los aspectos clave de los enfoques de la enseñanza: los elementos que intervienen en cualquier proceso de enseñanza; la "manera" de entender la enseñanza; el concepto de persona educada; la compatibilidad o incompatibilidad entre los enfoques; y se ofrece una síntesis de los aspectos más destacados de cada enfoque. En tercer lugar se realiza la propuesta metodológica a desarrollar con el alumnado. Por último, la conclusión es que la finalidad del proceso de enseñanza-aprendizaje define el enfoque de enseñanza asumido y/o puesto en práctica por el profesorado.

Palabras clave: Teorías educativas | Preparación del profesorado | Enseñanza

\begin{abstract}
The purpose of the article is to provide a methodology to facilitate the understanding, evaluation and to discern the teaching approaches proposed by Fenstermacher and Soltis (1998). First, several ways of conceiving and classifying the theories of teaching are mentioned. Secondly the key aspects of teaching approaches are highlighted: the elements involved in any process of education; the way teaching is understood; the concept of educated person; compatibility or incompatibility between approaches; and a summary of the most important aspects of each approach is provided. Thirdly a methodological proposal to be developed with students is outlined. Finally, it is concluded that the purpose of the teaching-learning process defines the approach to teaching adopted and/or implemented by teachers.
\end{abstract}

Key words: Educational Theories | Teacher Training | Teaching

\section{Introducción}

Este artículo es una propuesta para la enseñanza y el aprendizaje del conocimiento representacional o síntesis de conocimiento, en definitiva, de las teorías de enseñanza. Son las teorías que el sujeto conoce o reconoce porque su naturaleza es explícita, pero no necesariamente comparte. La diferencia con el conocimiento atribucional, síntesis de creencias o teorías implícitas (Rodrigo, Rodríguez y Marrero, 1993; Marrero, 2009) radica en la tarea que el sujeto tiene que afrontar (no en el 
contenido), es decir, es una tarea teórica para las síntesis representacionales o una tarea pragmática para las atribucionales.

Este artículo defiende que los programas de formación del profesorado deberían permitir aproximarse a las propias teorías y creencias para darle la oportunidad de reelaborarlas y cambiarlas. Es importante capacitar al futuro maestro o a la futura maestra para "remover la incapacidad de aprender de su propia experiencia" (Rodríguez, 1999, p. 137). Según Pozo, Scheuer, Mateos y Pérez (2006) consideran que el cambio de las teorías implícitas "sólo puede producirse por procesos de aprendizaje explícito" (Pozo et al, 2006, p. 111).

Siguiendo los postulados de Habermas, Carr y Kemmis (1988) y Carr (1990) conceptualizan el trabajo de la enseñanza como una actividad que puede estar guiada desde tres posiciones distintas: la racionalidad técnica, la racionalidad práctica y la racionalidad crítica. En este artículo se realiza una propuesta metodológica para trabajar con el alumnado los enfoques que definen Fenstermacher y Soltis (1998). Estos autores se inspiran en las perspectivas clásicas y contemporáneas (racionalidades pedagógicas) pero con un enfoque práctico y cercano a la realidad de un aula y a la manera de hacer del profesorado. Pretenden dar a conocer al futuro profesorado las potencialidades e inconvenientes de cada uno de los enfoques de la enseñanza mediante una actividad continua de reflexión sobre los mismos. Dicha reflexión, es la base para la elección y aplicación de los enfoques, donde el futuro profesorado entenderá que su manera de ser docente propicia un tipo de enseñanza para alcanzar unos propósitos determinados, lo cual, también implica una manera de entender el tipo de ciudadano que es enseñado.

\section{Enfoques de la enseñanza}

Los enfoques son diferentes maneras de pensar sobre la enseñanza. Son concepciones sobre lo que es enseñar y sobre lo que debería ser enseñar (Fenstermacher y Soltis, 1998). El profesorado, no siempre es consciente del enfoque que aplica cuando enseña, pero es necesario que conozca las diversas posibilidades que hay para que pueda tomar una decisión reflexionada sobre la manera en que quiere enseñar. Puede haber docentes muy diferentes pero igualmente eficaces en la consecución de los objetivos. No hay una única manera correcta de abordar la enseñanza (Fenstermacher y Soltis, 1998).

Ese saber sobre diferentes enfoques docentes permite a cualquier profesional elegir la propia manera de enseñar (Fenstermacher y Soltis, 1998).

\section{Elementos del proceso de enseñanza}

En cualquier proceso de enseñanza-aprendizaje, están presentes los siguientes elementos: docente, acción de enseñar, discente o estudiante, contenido y propósito o fin. Puede establecerse la siguiente fórmula: " $D \varphi E x y$ " (Fenstermacher y Soltis, 1998, p. 26). Donde $D=$ Docente, $\varphi=$ Letra fi griega que significa acción, $E=$ Estudiante, $x=$ Contenido e $y=$ Propósito o fin.

Los autores ponen énfasis en el propósito o fin del proceso de enseñanza-aprendizaje. El cual dependerá de la manera del profesorado. 


\section{La "manera" de entender la enseñanza}

La "manera" es una disposición (modalidad, estilo) relativamente estable que guía la actuación en determinadas circunstancias. Es decir, "la manera de entender la docencia tendrá un gran efecto en lo que haga el docente" (Fenstermacher y Soltis, 1998, p. 15).

Las "maneras" son modos coherentes de conducta, modos de enseñar que no dependen de la materia y son aplicables a todos los campos. La "manera" es parte del contenido porque mientras éste se comunica, también se enseña el modo en qué habrá de enfocarse y tratarse (Marhuenda, 2000; Navas, 2008).

\section{Concepto de persona educada}

Fenstermacher y Soltis (1998) invitan a imaginar que las personas pueden recibir reconocimiento como Persona Educada. La metáfora de la posesión de dicho reconocimiento ayuda a comprender el proceso de enseñanza-aprendizaje al que puede dar lugar la concepción del profesorado sobre la enseñanza y su propósito. Así, la primera tarea que debe afrontar todo profesorado es "llegar a ciertas conclusiones sobre la naturaleza y el objetivo de ser una persona educada y el lugar que ocupa la escolaridad en el proceso de alcanzar esa condición" (Fenstermacher y Soltis, 1998, p. 113).

\section{Compatibilidad o incompatibilidad entre los enfoques}

En las primeras páginas del libro Fenstermacher y Soltis (1998) sostienen que los enfoques son incompatibles incluso llegan a afirmar que no es posible combinar los enfoques porque parten de "concepciones muy diferentes de lo que significa ser una persona" (Fenstermacher y Soltis, 1998, p. 65).

Coincidimos en que la exposición de los mismos como incompatibles y excluyentes es "un modo de clarificar sus diferencias e ilustrar el poder y la atracción que tiene cada uno de ellos" (Fenstermacher y Soltis, 1998, p. 113) y las fronteras que los separan son construcciones académicas que "no tienen que constituir necesariamente barreras para la acción práctica" (Fenstermacher y Soltis, 1998, p. 114). En definitiva, es posible compatibilizar los enfoques de enseñanza en la práctica. Cada enfoque supone unos valores que pueden aplicarse a momentos diferentes o en una misma situación, aunque desde dimensiones diferentes.

\section{Síntesis de los enfoques de la enseñanza}

Los tres enfoques son esenciales, la decisión de cuál sería primario varía según el objetivo o tipo de comprensión que el profesorado quiera estimular en el alumnado (Fenstermacher y Soltis, 1998). En el cuadro 1 se muestra una síntesis de los tres enfoques de la enseñanza. 
Cuadro 1. Síntesis de los enfoques de la enseñanza

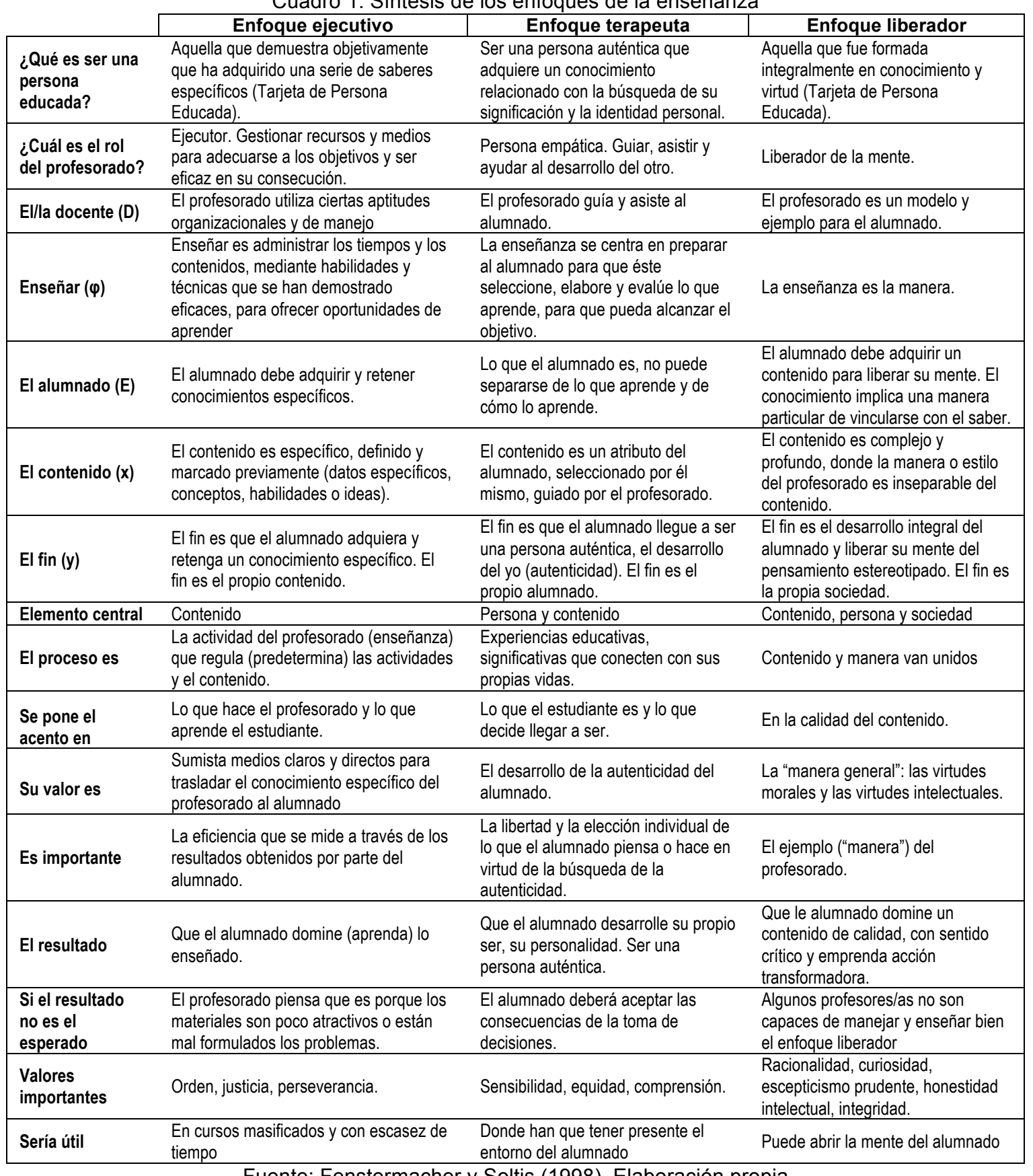

Fuente: Fenstermacher y Soltis (1998). Elaboración propia

\section{Propuesta metodológica para la comprensión de los enfoques de la enseñanza}

- Explicación teórica de los enfoques de la enseñanza según Fenstermacher y Soltis (1998): concepto, elementos del proceso de enseñanza, la "manera", persona educada, compatibilidad de los enfoques.

- Previa lectura por parte del alumnado de los capítulos 2, 3 y 4 de Fenstermacher y Soltis (1998) se analizan (y se explican) las características de cada uno de los enfoques resolviendo dudas surgidas en el alumnado y se analiza un caso propio de cada uno. La lectura del caso permite al alumnado ir identificando las características propias de cada enfoque, tanto las que se identifican claramente como las que crean confusión en la identificación del enfoque asumido y/o empleado por el profesorado del caso. 
- Caso "Aprendizaje individualizado" (enfoque ejecutivo).

- Caso "Curar la timidez" (enfoque terapeuta)

- Caso “¿Libertad de expresión?" (enfoque liberador)

- Trabajo individual y luego grupal para identificar el enfoque y sus características en 6 casos: Un nuevo equipo de ciencia, ¿Cuándo el control es excesivo?, ¿Qué estándar deberíamos usar?, Enseñar literatura "relevante", ¿Demasiado joven para ser crítico? y Educación para la vida. Puesta en común y resolución de dudas.

- Conclusiones.

- Propuesta individual/grupal de imágenes para la representación de los enfoques de la enseñanza.

- Reflexión personal individual por escrito sobre qué tipo de docente les gustaría ser en un futuro.

- Tarea: el alumnado deberá redactar un caso de algún profesor o profesora en la que se incluyan las características del enfoque de enseñanza que asume y/o emplea en la práctica educativa. En principio, sólo poner las características propias del enfoque elegido. Pero se recomienda que el caso incluya otras características que puedan pertenecer a otros enfoques, por ejemplo, incluyendo en el texto que el profesor o profesora hace "x" y no hace ni "y" ni "z". Para una mayor utilidad para el alumnado se recomienda ir señalando qué características son de cada enfoque, por ejemplo: texto normal para el enfoque elegido y texto cursivo y texto subrayado para los otros dos enfoques.

\section{Conclusión}

En conclusión, es la finalidad del proceso de enseñanza-aprendizaje la que define el enfoque de enseñanza asumido y/o puesto en práctica por el profesorado.

Las aportaciones teóricas de los enfoques de la enseñanza nos llevan a concluir que "lo que hacemos como docentes es el resultado de la influencia combinada de 4 factores: nosotros mismos, los estudiantes, el contenido y el contexto" (Fenstermacher y Soltis, 1998, p. 153). Lo importante es que "usted, el futuro docente, tome decisiones conscientes, cuidadosamente pensadas, sobre el tipo de docente que desea ser, y que nunca deje de reflexionar sobre el tipo de docente que está siempre en proceso de llegar a ser" (Fenstermacher y Soltis, 1998, p. 154). Esta ha sido la intención del presente artículo: proporcionar una propuesta práctica que facilite entender, valorar y discernir las teorías o los enfoques de la enseñanza. En definitiva, considero esencial dar la oportunidad de reflexionar sobre los diferentes enfoques de la enseñanza, para que cada docente llegue a su concepción y a su opinión reflexiva y deliberadamente elegida (Fenstermacher y Soltis, 1998).

\section{Referencias}

Carr, W., \& Kemmis, S. (1988). Teoría crítica de la enseñanza. La investigación-acción en la formación del profesorado. Barcelona: Martínez Roca. ISBN: 8427011822.

Carr, W. (1990). Cambio educativo y desarrollo profesional. Investigación en la escuela, 11, 312. http://www.investigacionenlaescuela.es/articulos/11/R11_1.pdf

Fenstermacher, G.D., \& Soltis, J.F. (1998). Enfoques de la enseñanza. Buenos Aires: Amorrortu. ISBN: 9505188056.

Marhuenda, F. (2000). Didáctica general. Madrid: Ediciones de la Torre. ISBN: 8479602899. 
Marrero, J. (Ed) (2009). El pensamiento reencontrado. Barcelona: Octaedro. ISBN: 9788480639941.

Navas, A. (2008). Estudio de la práctica pedagógica en garantía social (Tesis doctoral). València: Universitat de València. ISBN: 9788437071688.

Pozo, J.I., Scheuer, N., Mateos, M. \& Pérez, M. P. (2006). Las teorías implícitas sobre el aprendizaje y la enseñanza. En J. I. Pozo et al J. I. Pozo, N. Scheuer, M. P. Pérez, M. Mateos, E. Martín y M. Cruz, Nuevas formas de pensar la enseñanza y el aprendizaje: las concepciones de profesores y alumnos (pp. 95-132) Barcelona: Grao. ISBN: 8478274324.

Rodrigo, M.J., Rodríguez, A. \& Marrero, J. (1993). Las teorías implícitas. Una aproximación al conocimiento cotidiano. Madrid: Visor. ISBN: 8477740933.

Rodríguez, J.M. (1999). Las teorías implícitas sobre la enseñanza de los profesores en formación antes de las prácticas: el caso de Alicia. XXI: Revista de Educación, 1(2), 133-156. http://www.uhu.es/publicaciones/ojs/index.php/xxi/article/view/556

$\square$ Citar:

Ros-Garrido, A. (2015). Una propuesta práctica para entender, valorar y discernir los enfoques de la enseñanza. ReiDoCrea, 4 , $48-53$. http://hdl.handle.net/10481/35121

http://www.ugr.es/ reidocrea/ReiDoCrea-Vol.4-Art.7-Ros.pdf 